\title{
Prediction of the Material Composition of the VVER-type Reactor Burned Pellet with Use of Neutron-Physical Codes
}

\section{Mikhail Ternovykh¹, Ivan Saldikov¹, Georgy Tikhomirov ${ }^{1}$ and Alexander Gerasimov²}

${ }^{1}$ National Research Nuclear University MEPhl (Moscow Engineering Physics Institute), Department of Theoretical and Experimental Physics of Nuclear Reactors, Kashirskoe shosse 31, Moscow, 115409, Russia

${ }^{2}$ NRC Kurchatov' Institute - Institute for Theoretical and Experimental Physics, Department of nuclear reactors, Moscow, Russia

\section{Abstract}

The purpose of neutron-physical calculations is typically isotopic composition of the fuel elements. However, in solving materials science problems related to nuclear fuel, researchers are usually interested in elemental composition of the fuel pellets,

Corresponding Author:

Ivan Saldikov

ISSaldikov@mephi.ru

Received: 21 December 2017

Accepted: 15 April 2018

Published: 6 May 2018

Publishing services provided by Knowledge

(c) Mikhail Ternovykh et al. This article is distributed under the terms of the Creative Commons Attribution License, which permits unrestricted use and redistribution provided that the original author and source are credited.

Selection and Peer-review under the responsibility of the MIE-2017 Conference Committee. because the chemical and thermal physic properties are the same for different isotopes of one chemical element. Nevertheless, for modeling of the elemental composition one should perform calculation of the isotopic composition and carry out the summation over all isotopes of a given chemical element. The development of computational tools allows the use of improved methods and codes, which held the consequent solution of tasks of heat conduction, neutron transport, and kinetics of nuclides transformation. Thus the calculations take into account the dependence of the thermal conductivity from the changing isotopic composition and fuel burnup. This allows to perform neutron-physical and thermal-physical calculations of the reactor with detailed temperature distribution, taking into account temperature dependence of thermal conductivity and other characteristics. This approach was applied to calculations of the fuel pellet of the VVER type reactor and calculation of its elemental composition.

Keywords: materials science, elemental composition, fuel pellet.

\section{INTRODUCTION}

Fission products and actinides are accumulated in nuclear fuel during the process of burning. The number of isotopes that can occur in spent nuclear fuel, is a few hundred. Most of them are radioactive. The yield of a particular isotope of the fission product depends on the fissile nucleus. The mass of fission product in the fuel depends on its 
nuclear properties and burnup. Actinides appear in spent nuclear fuel from initial heavy nuclei by the reaction of radiative capture of neutrons and radioactive decays.

Material studies of spent fuel pellets do not require isotopic composition, but require elemental composition, obtained by summation of all the accumulated isotopes of a given chemical element. This is due to the fact that the chemical and thermal properties are the same for different isotopes of one element. Therefore, to obtain the elemental composition of the fuel pellet it is necessary to calculate the isotopic composition.

Modern computing tools and developed methods and software complexes allow to perform combined neutron-physical and thermal calculations taking into account the dependence of the thermal conductivity of the material of fuel pellet from changing isotopic composition and burnup. This increases the accuracy of the calculation of isotopic composition of the pellet and thus the accuracy of the elemental composition.

Simulators of fuel pellets are used for experimental research instead of real fuel pellets having high radioactivity. Simulators of fuel pellets are made by the following way. According calculated elemental composition, elements-fission products accumulated in significant quantities are selected. These elements will be included into simulator of fuel pellet. For each of these elements, stable isotope should be taken in the amount obtained in calculated elemental composition. Chemical elements - actinides for the fabrication of the simulator are replaced by stable elements from the lanthanides group with similar chemical and thermal properties. The experts in materials science have already solved problems of such replacement. Therefore, the task of experts on reactor calculation is to perform calculations of isotopic composition of fission products and actinides of spent fuel pellets.

\section{ALGORITHMS AND METHODS}

The combined use of neutron-physical and thermal calculation begins with preliminary calculation of the temperature distribution along the radius of the cylindrical fuel rod. In simple calculations, the coefficient of thermal conductivity is taken constant. In combined calculations we must take into account that the coefficient of thermal conductivity of oxide nuclear fuel depends on the temperature and burnup (Fig. 1, 2). In addition, the energy and burnup unevenly changes along the radius of the fuel rod in the process of fuel burning. The swelling of the fuel pellet with deep burnup leads to a reduction of the gap between the fuel pellet and cladding. 


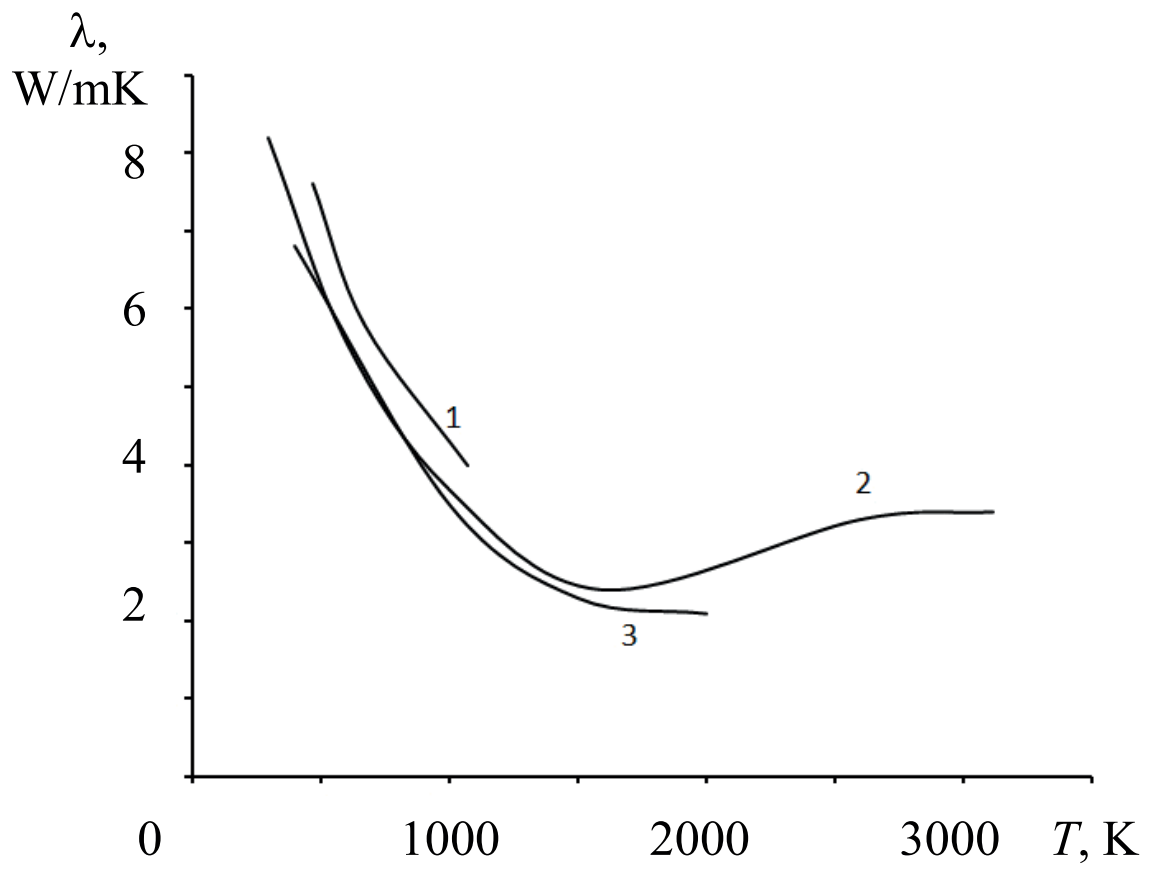

Figure 1: Coefficient of thermal conductivity of oxide nuclear fuel depending from temperature. 1 - data from [1], 2 - from [12], 3 - from [3].

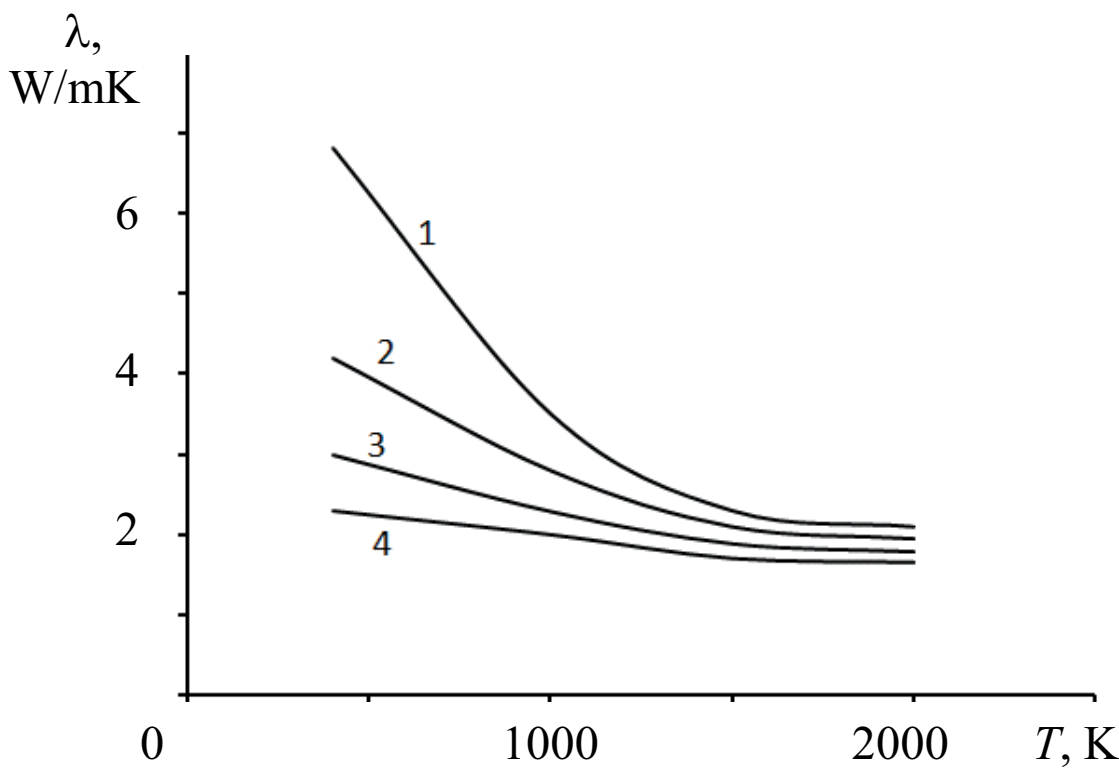

Figure 2: Coefficient of thermal conductivity of oxide nuclear fuel depending from temperature for different burnups: 1 - fresh fuel, 2 - burnup 30, 3-60, 4 - $90 \mathrm{MWd} / \mathrm{kgU}$.

Because of this dependence, the heat conduction equation is nonlinear. In the cylindrical geometry it is:

$$
\frac{1}{r} \cdot \frac{\partial}{\partial r} \lambda(T(r), B) \cdot r \cdot \frac{\partial}{\partial r} T(r)+q_{V}(r)=0
$$


where $\lambda(T(r), B)$ - coefficient of thermal conductivity of fuel depending from temperature, $q_{v}(r)$ - thermal source, $T(r)$ - temperature.

Several methods can be used for solutions of this nonlinear equation. One of them [4] proposes to replace the coefficient of thermal conductivity by approximate dependence

$$
\lambda(T)=\frac{1}{A+B \cdot T}
$$

where $A$ and $B$ are constants depending on the fuel properties and its mode of operation, and $T$ is the temperature. The values of the constants $A$ and $B$ can be obtained by approximation of experimental data. Another method requires dividing the fuel pellet into annular zones. In each zone the coefficients of thermal conductivity remain constant, i.e.

$$
\lambda(T(r))=\left\{\lambda\left(T_{i}\right)\right\}=\left\{\lambda_{i}\right\}
$$

Then the thermal conductivity equation becomes linear within each zone. However, in this case we need to use iterative procedure. Each iteration specifies the value of thermal conductivity factor in each layer. This allows to consider the dependence of thermal conductivity factor on temperature. Similarly, we can proceed with the dependence of thermal conductivity factor on fuel burnup : in each step of burnup to take from the table the new value of the factor of thermal conductivity and insert it into the equation to find the temperature.

System of equations of isotope kinetics is formulated for vector of isotope concentrations of nuclides $\bar{\rho}^{i}(t)$. Isotope concentrations in each spatial zone with number $i$ are assumed to be the same in all points of spatial sone.

$$
\frac{d \rho_{l}^{i}(t)}{d t}=\sum_{k} \lambda_{k \rightarrow l} \cdot \rho_{l}^{i}(t)-\lambda_{l} \cdot \rho_{l}^{i}(t)+\sum_{m} \rho_{m}^{i}(t) \cdot \sigma_{m \rightarrow l}^{i} \cdot \varphi^{i}-\rho_{l}^{i}(t) \cdot \sigma_{l}^{i} \cdot \varphi^{i}
$$

Each equation of the system of equations of isotope kinetics include the following values in addition to concentrations.

$\sigma_{l}^{i}$ - one-group cross section of incineration of isotope with number / in spatial zone with number $i$ due to nuclear reactions on $I$-th isotope.

$\sigma_{m \rightarrow l}^{i}$ - one-group cross section of appearance of isotope with number I in spatial zone with number $i$ due to nuclear reactions on $m$-th isotope.

$\varphi^{i}$ - one-group neutron flux in $i$-th spatial zone.

$\lambda_{l}$ - decay constant of $l$-th isotope

$\lambda_{k \rightarrow l}$ - decay constant of $k$-th isotope resulting in appearance of $l$-th isotope.

Vector of concentrations changes in process of burning of nuclear fuel. Concentrations of isotopes may vary in different spatial locations of the fuel core. For example, 
area with modified microstructure, so-called rim-zone appears in the outer layer of the fuel rod of thermal-neutron reactors. Its formation is associated with high concentration of fission products [5-7]. Therefore, application of constant concentrations over the whole fuel rod can lead to distortion of the simulation results. Along with isotope concentrations, other properties of fuel composition can vary with radius within fuel rod in the process of burnup and can influence on space distribution of the temperature. These variation of temperature don't take into account in the "classic" approach, and the process of formation of rim-zone can't be calculated.

In order to solve a system of equations of isotope kinetics, one must firstly calculate one-group fluxes $\varphi^{i}$ and the cross section of the reactions $\sigma_{l}^{i}$ and $\sigma_{m \rightarrow l}^{i}$. It is also necessary to know the decay constants $\lambda_{l}$ and $\lambda_{k \rightarrow l}$ for each nuclide and initial concentrations of isotopes $\rho_{l}^{i}$. After the solution of the equations of isotope kinetics, the new value of the concentration vector $\bar{\rho}^{i}(t)$ is obtained, which corresponds to a certain moment of time.

Developed method of combined neutron-physical and thermal calculation involves an iterative procedure in which calculations of isotope kinetics and thermal conductivity are performed step by step. This method is described in detail in [8].

\section{ALGORITHMS AND CODES USED IN CALCULATIONS}

In the thermal calculation codes HEATING7, UNK_teplo, TempR_5 were used.

HEATING7 is multipurpose code for the solution of tasks of heat conduction $[9,10]$. The code is included in the complex SCALE [11]. HEATING can solve stationary and/or nonstationary task of heat conduction in one-, two- or three-dimensional rectangular, cylindrical, or spherical coordinates. Calculation model may include various materials. Thermal conductivity, density and energy of each material may depend on time and temperature. The conductivity may also be anisotropic. Thermal properties of materials can be entered by the user or can be retrieved from the library of material properties.

UNK_teplo - software for the solution of task of heat conduction. The code is included in the complex UNK [9]. This code can solve a stationary task of heat conduction in one-dimensional cylindrical coordinates. Calculation model may include various materials. Thermal conductivity, the density of each material is specified separately for each layer. Thermal properties of materials can be entered by the user. The calculation of temperatures in the complex UNK is made simultaneously with the calculation of burnup.

TempR_5 allows to calculate temperature in cylindrical fuel element with piecewise constant thermal conductivity factor. The temperature distribution in each layer 
obtained from the analytical solution of the heat equation with assigned values of radius, thermal conductivity factor and temperature. The results of the calculation are the average values of temperature in layers, the temperature at points between the layers and in the center of the fuel element.

\section{RESULTS OF CALCULATIONS OF TEST TASIS}

The use of an integrated method using joint calculation of neutron-physical and thermal characteristics is illustrated by calculations of the temperature distribution along the radius of the fuel rod of the VVER-1000 reactor. Tasks were solved in onedimensional cylindrical geometry.

Model of the elementary cell of the VVER-1000 is taken as base model. The diameter of the central hole of the fuel pellet was taken as $1.5 \mathrm{~mm}$, the external diameter of the pellet $7.55 \mathrm{~mm}$; internal and external diameters of the cladding 7.72 and $9.17 \mathrm{~mm}$; the pitch of the triangular lattice of rods $12.75 \mathrm{~mm}$, temperature of coolant $575.7 \mathrm{~K}$. For calculations, fuel rod was divided on 11 radial layers.

The temperature of the outer surface of the cladding was the same for all calculations. It was equal to the temperature of the coolant $575.7 \mathrm{~K}$. The thermal conductivity factor was taken as $0.35 \mathrm{~W} / \mathrm{mK}$ for the center hole and the gas gap between the fuel rod and cladding, and as $20.42 \mathrm{~W} / \mathrm{mK}$ for cladding. These values were the same for all calculations.

The advantage of the developed technique, which allows take into account the dependence of thermal conductivity factor on temperature and fuel burnup is demonstrated by the results presented in Fig. 3. Curve 1 corresponded to the traditional approach when $\lambda$ was taken to be constant throughout the fuel rod. It was evaluated for the average temperature in the rod $1000 \mathrm{~K}$. Curve 2 corresponded to the application of the developed technique, but in this case only the dependence $\lambda(T)$ is taken into account at burnup $B=0$. The dependence $\lambda(T, B)$ was taken into account for curves 3 and 4. Calculations were performed at $B=60$ (curve 3) and $120 \mathrm{MW} \cdot$ day/KGU (curve 4 ). It was assumed for all four cases that no gas gap was there between fuel rod and cladding, and energy release density $q_{v}=388 \mathrm{~W} / \mathrm{cm}^{3}$ was constant over the fuel rod.

The results presented in Fig.3 can be easily interpreted using data on $\lambda(T, B)$ from Fig.2. For the curve 1 the temperature decreases from the center to the periphery of the fuel rod. Peripheral temperature is determined by the coolant temperature of 575 $\mathrm{K}$.

For the curve 2 when we consider $\lambda(T)$ at $B=0$ (the upper curve 1 in Fig.2), the $\lambda$ increases sharply due to temperature decrease in going from the center of the fuel rod 


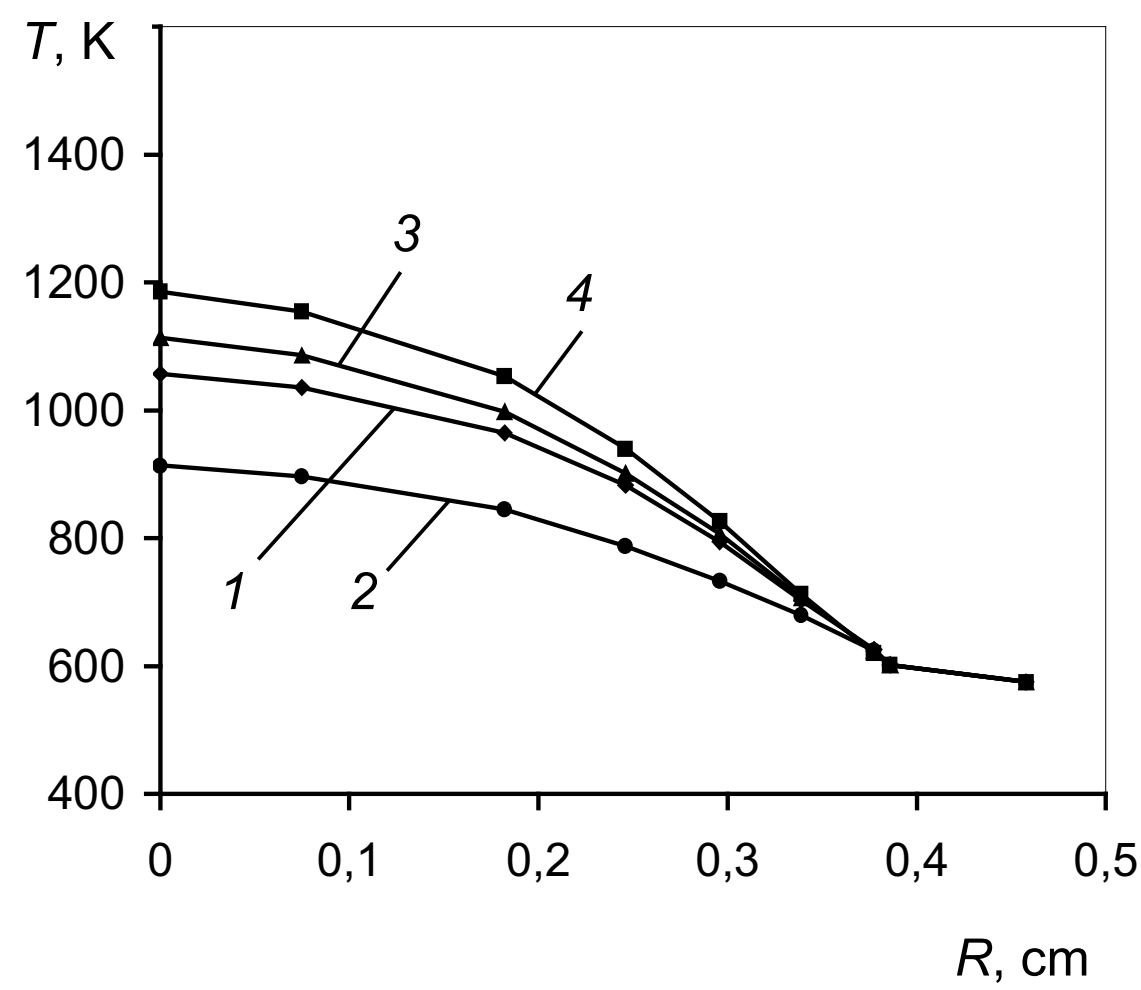

Figure $3: \lambda=$ const $(1), \lambda(T)$ is considered $(2), \lambda(T, B)$ for $B=60 \mathrm{MWd} / \mathrm{kg}$ is considered $(3), \lambda(T, B)$ for $B=$ $120 \mathrm{MWd} / \mathrm{kg}$ is considered (4).

to its periphery. Since the peripheral temperature is specified, the temperature at the center is lower than in case 1 . The curve 2 lies below the curve 1 .

For the curve 3 corresponding to the curve 3 in Fig. 2 the $\lambda$ values are much less than for curves 1 and 2 . The increase of $\lambda$ in going from the center to the periphery of fuel rod is slower. Since the energy release density is the same in all cases and peripheral temperature is specified, the temperature in the center of the rod is higher than for curve 1. The curve 3 in Fig.3 lies above the curve 1.

For the curve 4 (curve $\lambda(T, B)$ is more flatter than curve 4 in Fig.2) similar arguments show that the temperature in the center of the rod is higher than for curve 3 . The curve 4 in Fig.3 lies above the curve 3.

TABLE 1: Fission products with maximum accumulation in spent fuel of VVER. 
TABLE 2: Masses of elements in spent fuel of VVER at different burnups, g/kg U.

\begin{tabular}{|c|c|c|c|}
\hline \multirow[t]{2}{*}{ Chemical element } & \multicolumn{3}{|c|}{ Burnup, MWd/kgU } \\
\hline & 60 & 80 & 120 \\
\hline \multicolumn{4}{|c|}{ Fission products } \\
\hline Ba & 2,64 & 3,65 & 5,91 \\
\hline $\mathrm{Ce}$ & 4,79 & 6,11 & 8,72 \\
\hline Cs & 5,18 & 6,69 & 9,41 \\
\hline La & 2,19 & 2,85 & 4,12 \\
\hline Mo & 5,91 & 7,80 & 11,45 \\
\hline Nd & 6,74 & 8,98 & 13,35 \\
\hline Pd & 2,56 & 4,10 & 7,69 \\
\hline Ru & 4,60 & 6,41 & 10,21 \\
\hline Xe & 9,63 & 12,92 & 19,53 \\
\hline $\mathrm{Zr}$ & 6,28 & 7,96 & 11,03 \\
\hline Sum over $30 \mathrm{FP}$ & 61,94 & 82,2 & 122,40 \\
\hline \multicolumn{4}{|c|}{ Actinides } \\
\hline$U$ & 920,30 & 897,01 & 852,56 \\
\hline $\mathrm{Np}$ & 1,14 & 1,43 & 1,63 \\
\hline Pu & 15,75 & 17,88 & 20,49 \\
\hline Am & 0,43 & 0,76 & 1,38 \\
\hline $\mathrm{Cm}$ & 0,22 & 0,58 & 1,76 \\
\hline
\end{tabular}

\section{CALCULATIONS OF ELEMENTAL COMPOSITION OF FUEL PELLET OF VVER-1000}

Algorithms and results [12-14] were used to calculate the elemental composition of the VVER-1000 fuel core for a detailed spatial analysis of the burnup, considering temperature dependencies. Studies of the yields of fission products in fissions of ${ }^{235} \mathrm{U}$, ${ }^{238} \mathrm{U},{ }^{239} \mathrm{Pu}$ and ${ }^{241} \mathrm{Pu}$ allowed us to choose 30 chemical elements whose mass in spent fuel with burnup of 50 to $120 \mathrm{MWd} / \mathrm{kgU}$ makes not less than $98 \%$. 10 elements with maximum masses were selected from these 30 ones. These elements are listed in table 1 in descending order of mass.

The table 2 presents values of the masses of these ten fission products and the main actinides in spent nuclear fuel with burnup of 60,80 and $120 \mathrm{MWd} / \mathrm{kg}$. Fuel pellet with 
TABLE 3: Masses of elements at burnup of $60 \mathrm{MWd} / \mathrm{kg}$ with division in radial layers, g/k $\mathrm{U}$.

\begin{tabular}{|c|c|c|c|c|c|}
\hline Element & 1 (internal layer) & 2 (200 mkm) & $3(100 \mathrm{mkm})$ & $4(100 \mathrm{mkm})$ & $5(100 \mathrm{mkm})$ \\
\hline \multicolumn{6}{|c|}{ Fission products } \\
\hline $\mathrm{Ba}$ & 2,53 & 2,79 & 2,97 & 3,30 & 4,14 \\
\hline $\mathrm{Ce}$ & 4,47 & 4,92 & 5,23 & 5,80 & 7,27 \\
\hline Cs & 4,91 & 5,42 & 5,79 & 6,48 & 8,27 \\
\hline La & 2,05 & 2,26 & 2,40 & 2,67 & 3,34 \\
\hline Mo & 5,56 & 6,11 & 6,50 & 7,20 & 9,02 \\
\hline $\mathrm{Nd}$ & 6,41 & 7,00 & 7,40 & 8,14 & 10,03 \\
\hline Pd & 2,32 & 2,78 & 3,11 & 3,73 & 5,32 \\
\hline Ru & 4,17 & 4,74 & 5,15 & 5,90 & 7,82 \\
\hline $\mathrm{Xe}$ & 8,89 & 9,90 & 10,60 & 11,89 & 15,21 \\
\hline $\mathrm{Zr}$ & 5,95 & 6,41 & 6,72 & 7,29 & 8,75 \\
\hline Sum over $30 \mathrm{FP}$ & 58,08 & 64,24 & 68,49 & 76,46 & 96,86 \\
\hline \multicolumn{6}{|c|}{ Actinides } \\
\hline$U$ & 925,3 & 916,0 & 909,2 & 896,5 & 864,0 \\
\hline $\mathrm{Np}$ & 1,05 & 1,17 & 1,22 & 1,30 & 1,42 \\
\hline Pu & 15,00 & 17,79 & 20,12 & 24,67 & 36,14 \\
\hline Am & 0,369 & 0,492 & 0,575 & 0,729 & 1,127 \\
\hline $\mathrm{Cm}$ & 0,189 & 0,258 & 0,302 & 0,385 & 0,601 \\
\hline
\end{tabular}

$5 \%{ }^{235} \mathrm{U}$ was considered as the initial fuel. For comparison, the sum in the last line of the fission products table was taken for 30 main fission products

Tables 3, 4 present masses of ten main fission products and main actinides for burnup of 60 and $120 \mathrm{MWd} / \mathrm{kg}$ with division of fuel pellet in radial layers. Four peripheral layers with thickness of 100, 100, 100, $200 \mathrm{mkm}$, and the rest of the pellet was the inner layer. Note that the peripheral layers were a small part of the radius of fuel pellet. This allowed to show in detail the change in the accumulation of nuclides in the peripheral part of the fuel pellet

Fig. 4 presents the average over volume of the fuel pellet masses of main ten fission products for different burnup. 
TABLE 4: Masses of elements at burnup of $120 \mathrm{MWd} / \mathrm{kg}$ with division in radial layers, $\mathrm{g} / \mathrm{kg} \mathrm{U}$.

\begin{tabular}{|c|c|c|c|c|c|}
\hline Element & 1 (internal layer) & 2 (200 mkm) & 3 (100 mkm) & $4(100 \mathrm{mkm})$ & $5(100 \mathrm{mkm})$ \\
\hline \multicolumn{6}{|c|}{ Fission products } \\
\hline $\mathrm{Ba}$ & 5.58 & 6.35 & 6.89 & 7.91 & 10.45 \\
\hline $\mathrm{Ce}$ & 7.99 & 9.07 & 9.86 & 11.34 & 14.99 \\
\hline Cs & 8.72 & 9.95 & 10.88 & 12.62 & 16.95 \\
\hline La & 3.79 & 4.31 & 4.69 & 5.39 & 7.15 \\
\hline Mo & 10.53 & 11.94 & 12.97 & 14.90 & 19.68 \\
\hline Nd & 12.35 & 13.92 & 15.06 & 17.18 & 22.45 \\
\hline Pd & 6.79 & 8.25 & 9.29 & 11.24 & 16.10 \\
\hline Ru & 9.02 & 10.55 & 11.65 & 13.68 & 18.72 \\
\hline $\mathrm{Xe}$ & 17.58 & 20.21 & 22.10 & 25.64 & 34.42 \\
\hline $\mathrm{Zr}$ & 10.29 & 11.40 & 12.20 & 13.71 & 17.44 \\
\hline Sum over $30 \mathrm{FP}$ & 112.10 & 128.05 & 139.65 & 161.33 & 215.18 \\
\hline \multicolumn{6}{|c|}{ Actinides } \\
\hline U & 863.3 & 843.4 & 828.7 & 800.8 & 732.4 \\
\hline $\mathrm{Np}$ & 1.56 & 1.67 & 1.72 & 1.79 & 1.89 \\
\hline Pu & 20.70 & 23.69 & 26.41 & 31.62 & 43.73 \\
\hline Am & 1.14 & 1.50 & 1.74 & 2.19 & 3.31 \\
\hline $\mathrm{Cm}$ & 1.41 & 1.93 & 2.26 & 2.88 & 4.44 \\
\hline
\end{tabular}

\section{CONCLUSION}

The results of calculation of the elemental composition of fuel pellet of VVER show that masses of fission products and actinides in the fuel can be obtained with high accuracy and with division into the required spatial layers. High accuracy of calculations was due to the application of the developed method, combining neutron-physical and thermal calculation, which took into account the dependence of heat conductivity on the isotopic composition of the fuel and burnup. The obtained results were used for modeling of simulators of fission products and actinides for experiments to study the thermal physics properties of the fuel pellets in NRNU MEPhI.

Authors acknowledge support of MEPhl Academic Excellence Project (contract No. $02.003 .21 .0005,27.08 .2013)$. 


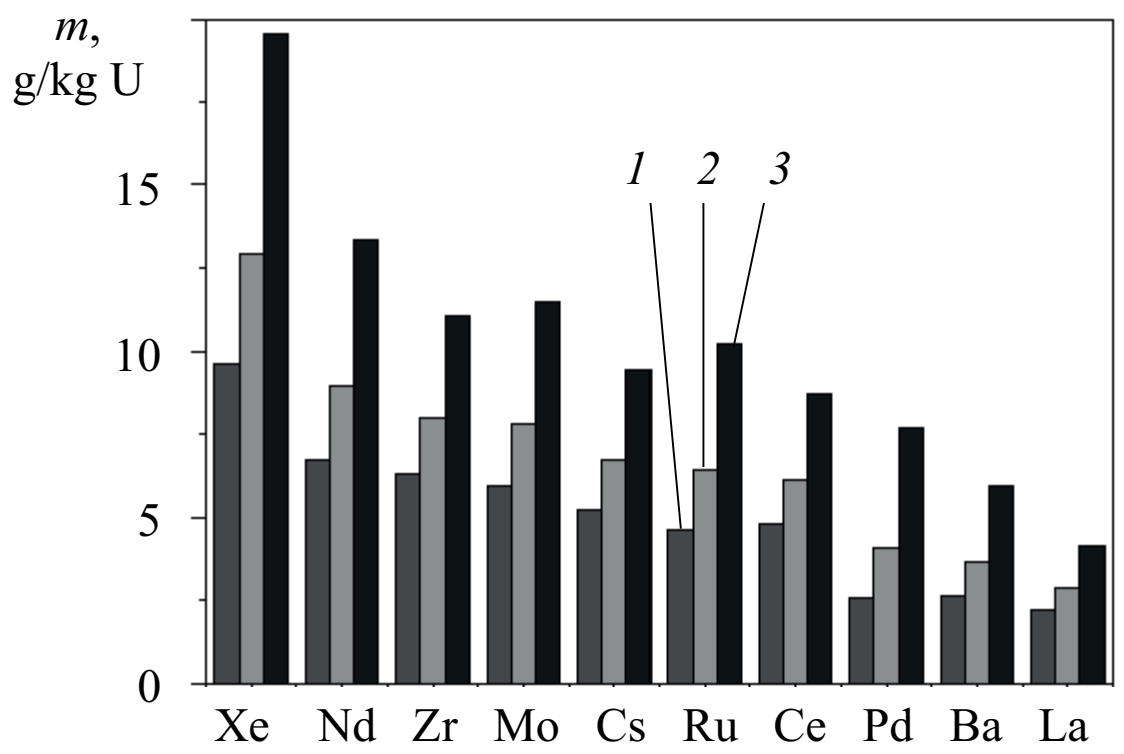

Figure 4: Masses of ten fission products for three burnups: $1-60,2-80,3-120 \mathrm{MWd} / \mathrm{kgU}$.

\section{References}

[1] Kurina I.S., Popov V.V., Rumyantsev V.N. Investigation of the properties of modified uranium dioxide. Atomic Energy. 2006. V. 101. No 5. pp. 802-808.

[12] Fink J.K., Chazanov M.G, Leibovitz L.J. Thermophysical properties of uranium dioxide. J. Nucl. Mater. 1981, V. 102, pp.17-25.

[3] Likhansky V. V., Aliev T. N., Evdokimov I. A. Modeling of the behavior of $\mathrm{UO}_{2}$ fuel for operating conditions in light water reactors. Nuclear physics and engineering, 2010, V. 1, No 2, pp. 104-122.

[4] Alyushin V.M., Baranov V.G., Kudryashov N.A., et al. Numerical modeling of the temperature distribution in a VVER fuel element. Atomic Energy, 2010, V.108, pp.184-193.

[5] J. Piron, B. Bordin, G. Geoffroy, et al., Proc. of the International Topical Meeting on Light Water Reactor Fuel Performance. Florida, USA, April 17-21, 321-327 (1994)

[6] A. Shcheglov, V. Sidorenko, V. Proselkov, S. Boi'shagin. Atomic Energy, 1996, V.80, pp.222-224

[7] Saldikov I., Tikhomirov G., Ternovykh M., and Gerasimov A. Computation methods and techniques for solution of coupled multiohysics roblems in precision calculations of VVER type reactors. Proceedings of the VII International Conference on Computational Methods for Coupled Problems in Science and Engineering COUPLED PROBLEMS 2017. Rhodes Islad, Greece, June 12 - 14, 2017. P. 1031-1041. 
[8] G.Tikhomirov, I.Saldikov, M.Ternovykh, A.Gerasimov. Consistent neutron-physical and thermal-physical calculations of fuel rods of VVER type reactors. EPJ Web of Conferences 153, 07036 (2017). https://doi.org/10.1051/epjconf/201715307036

[9] F.De Lillo, F.Cecconi, G.Lacorata, A.Vulpiani, EPL, 84 (2008) V. Davidenko, V. Tsibulsky. Proc. of the Int. Conf. on the Physics of Nuclear Science and Technology, Oct. 5-8, Long Island, New York, 1755-1760 (1998).

[10] K. Childs, HEATING 7.0 User's Manual, K/CSD/INF/90-32 (Martin Marietta Energy Systems, Inc., July 1990).

[11] SCALE: A Modular Code System for Performing Standardized Computer Analyses for Licensing Evaluation, Version 5, ORNL/TM-2005/39, I-III, ORNL (2005).

[12] Andrianov A.N., Baranov V.G., Tikhomirov G.V., Khlunov A.V. Simulation of neutronphysical processes in the surface layer of a fuel kernel. Atomic Energy. 2008. T. 104. № 6. C. $463-469$.

[13] Baranov V.G., Ternovykh M.Yu., Tikhomirov G.V., Khlunov A.V. Simulation of nuclearphysical processes in the surface layer of a fuel kernel with a consumable absorber. Atomic Energy. 2008. T. 105. № 6. C. 391-396.

[14] I S Saldikov, M Yu Ternovykh, P A Fomichenko, A S Gerasimov, The scheme for evaluation of isotopic composition of fast reactor core in closed nuclear fuel cycle, IOP Conf. Series: Journal of Physics: Conference Series, Volume 781 (2017), Number 1 